UNIVERSIDADE TECNOLOGICA FEDERAL DO PARANÁ

ESPECIALIZAÇÃO EM TECNOLOGIA JAVA

CRISTIANO HENRIQUE DUARTE

CUSTOMIZABLE AUTOMATIC LOWER COST FEEDER USING FREE

HARDWARE / SOFTWARE AND SCRAP

MONOGRAFIA DE ESPECIALIZAÇÃO

PATO BRANCO

2020 
Trabalho de Conclusão de Curso, apresentado ao Curso de Especialização Java, da Universidade Tecnológica Federal do Paraná, Campus Pato Branco, como requisito parcial para obtenção do título de Especialista.

Orientador: Prof. Fábio Favarim 
TERMO DE APROVAÇÃO

\title{
CUSTOMIZABLE AUTOMATIC LOWER COST FEEDER USING FREE HARDWARE / SOFTWARE AND SCRAP
}

\author{
por
}

\section{CRISTIANO HENRIQUE DUARTE}

A avaliação deste trabalho de conclusão de curso foi realizada em 02 de março de 2020, como requisito parcial para a obtenção do título de especialista em Tecnologia Java. Após a apresentação o candidato foi arguido pela banca examinadora composta pelos professores Fábio Favarim (orientador), Andreia Scariot Beulke e Vinicius Pegorini, membros de banca. Em seguida foi realizada a deliberação pela banca examinadora que considerou o trabalho aprovado.

Fábio Favarim
Prof. Orientador (UTFPR)

Andreia Scariot Beulke

(UTFPR)

Vinicius Pegorini

(UTFPR)

\footnotetext{
Vinicius Pegorini

Coordenador do curso
}

A Folha de Aprovação assinada encontra-se na Coordenação do Curso. 


\section{RESUMO}

Automação industrial está passando por uma grande transformação devido à facilidade de acesso à informação que temos hoje, bem como o uso popular de hardware / software livre. Projetos que foram previamente desenvolvidos por especialistas no campo hoje pode ser facilmente desenvolvido com equipamento de baixo custo. Este artigo apresenta o protótipo de um alimentador automático que faz uso de hardware de baixo custo, bem como software livre. Entre seus diferenciais é a personalização, o que lhe permite trabalhar tanto em ambientes online, sendo neste modelo remoto controlado através de um aplicativo Android, e em ambientes off-line, onde o controle é feito in loco pelo micro controlador. No final do trabalho foi desenvolvido um alimentador protótipo utilizando o material de sucata, uma MSP430F5529, um Raspberry Pi, no qual o custo total foi de 325 reais, com o seu custo médio inferior $80 \%$ em comparação com outros alimentadores comerciais mercado hoje.

Palavras-chave: Alimentador automático. Hardware livre. Software livre. 


\begin{abstract}
Industrial automation is undergoing a major transformation due to the ease of access to information we have today, as well as the popular use of free hardware / software. Projects that were previously developed by experts in the field today can easily be developed with low cost equipment. This paper presents the prototype of an automated feeder that makes use of low cost hardware as well as free software. Among its differentials is the customization, which allows it to work both in online environments, being in this model remote controlled through an Android app, and in offline environments, where the control is done inloco by the microcontroller. At the end of the work was developed a prototype feeder using scrap material, an MSP430F5529, a Raspberry $\mathrm{Pi}$, in which the total cost was 325 reais, with its average cost lower than 80 percent compared to other commercial feeders on the market today.
\end{abstract}

Keywords: Automatic feeder. Free hardware. Free software. 


\section{LISTA DE FIGURAS}

Figura 1 - a) Side view of the feeder. b) View of feeder output..............................................14

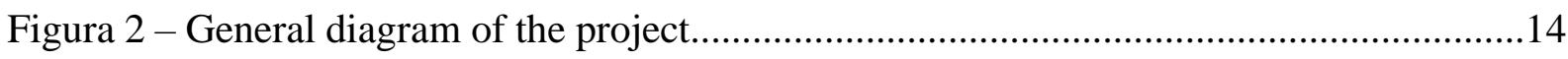

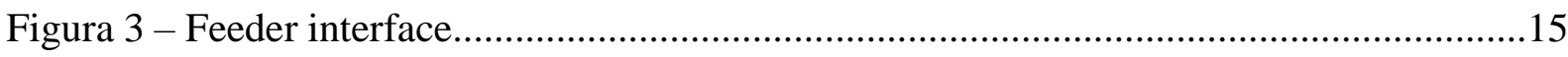

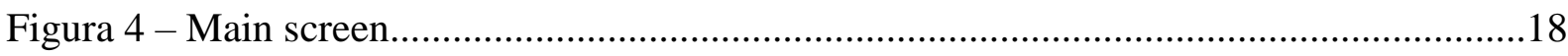

Figura 5 - Screen for setting the feeding times...............................................................19

Figura 6 - Screen for manual feeding and buzzer activation..............................................19 


\section{LISTA DE TABELAS}

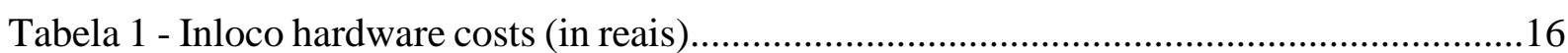




\section{LISTA DE SIGLAS}

$\begin{array}{ll}\text { GB } & \text { Giga Byte } \\ \text { GHZ } & \text { Giga Hertz } \\ \text { IO } & \text { Input/Output } \\ \text { KB } & \text { Kilobyte } \\ \text { LCD } & \text { Liquid Crystal Display } \\ \text { MAH } & \text { Milliamp Hours } \\ \text { MHZ } & \text { Mega Hertz } \\ \text { PVC } & \text { Polyvinyl chloride } \\ \text { RAM } & \text { Random Access Memory } \\ \text { UART } & \text { Universal Asynchrounous Receiver / Transmiter } \\ \text { USB } & \text { Universal Serial Bus }\end{array}$




\section{SUMÁRIO}

1. INTRODUÇÃO

2. RELATED WORKS 12

3. MATERIALS AND METHODS

4. RESULTS 17

4.1 Inloco 17

4.2 Middle $\quad 17$

$\begin{array}{ll}4.3 \text { App } & 17\end{array}$

4.4 Hardware costs $\quad 18$

5. CONCLUSIONS 20

6. REFERENCES 21 


\section{INTRODUCTION}

Today a word widely used in technological development is automation, which means using mechanical or electronic devices to facilitate human work. As an example we can mention the activation of lamps and the temperature control of environments, which can be automatic or performed remotely.

In the beginning, projects involving automation were developed by large companies, given the cost and complexity to accomplish them. Over the years, electronic components have become popular, reducing both size and cost, and increasing their applications in automation, allowing lay people to develop projects in the field of automation.

One example is the free hardware concept, which introduced simple-to-understand content with video explanations of how all the steps of the project were assembled. This gives rise to various ideas and encourages others to develop similar projects. Also, websites or companies that sell such products relate them to tutorials explaining use cases of these items, making the market for these products grow rapidly (S. DAVIDSON et al., 2004)

Nowadays, the possibilities for using automation are very large. Given the ubiquity of the Internet in most major centers, these developed devices can access real-time information, and this information can be anywhere in the world.

Possibilities include home use, where simple controls such as turning the lamps on and off at a distance, as well as complex operations such as detecting the mood of people in a particular environment to suggest ambient music, for example.

In agriculture, despite being often remote from large centers, automation can be inserted, as many electronic devices can operate on battery power for several days, and communication with servers on the Internet can occur intermittently. Among the possibilities is the activation and monitoring of greenhouses, animal counters and even remote controlled feeders.

In animal husbandry, one of the tasks that require the most human effort is feeding, because it requires a commitment from the person to perform this activity a number of times a day. In some scenarios, such as fish farming, the management of animals throughout their growth is limited to feeding, since there is no need to clean the place where they are present, and this activity can easily be replaced by an automatic feeder.

Automatic feeders with or without remote control already exist, such as those in (A. SUDOESTE, 2019), (PETSAFE, 2019), (J.-Y.JUNG,2016) and (PETNET,2019), however, they are commercial products and have a high added value, which makes such automation expensive, especially in small producers such as family farmers. The high cost of existing 
commercial products, which come to around 2,000 reais in Brazil, is the state-of-the-art technology used for development, but with the popularization of free and low cost hardware / software it is possible to create complex feeders even using scrap and cheap microcontrollers.

Thus, the present work presents the development of a low cost automatic animal feeder, focused for use in fish farming, but that could be easily adapted to other animals. This feeder will allow you to set feeding times and the amount of food to be dispensed. For ease of use, the feeder will have the option to work inloco, ie with its programming done via buttons and display on the feeder itself, or remotely using an Android mobile device via the Internet, using for premises from the Internet of Things. 


\section{RELATED WORKS}

SOH Z.H.C. (2017) features an automatic chicken feeder using the Arduino Uno microcontroller board. Arduino controls a servo motor that opens and closes a valve, allowing corn grains to pass from a storage container to the container the chickens feed on. The valve operates every eight hours and stays open for a few seconds to release a preset amount of grain. In addition, the board monitors a temperature sensor. Whenever the temperature falls below a threshold, light bulbs are fired to keep the grain temperature between 27 and 33 degrees Celsius, leaving them fresh. This device works in isolation without internet access.

KISHORE, K.K. (2017) proposes an automatic feeder for fish. The feed container is housed in a small boat equipped with a radio frequency transmitter and receiver and a video transmitter. In this way, from the lake shore, the fish farmer controls the movement of the boat through a remote control. The feed container has a water outlet, which contains a valve that can be opened or closed by a servo motor. The farmer can control the opening and closing of the valve as needed remotely through radio frequency. This work does not allow programming for automatic activation, depending on human interaction.

For systems that allow remote monitoring and control, (J.-Y.JUNG, 2016) introduces NutriPet. This feeder uses the Raspberry Pi board and applies to pets such as dogs and cats. Inside the pet food container is the board and a servo motor that is used to open or close the container. Opening or closing can be controlled by the animal by stepping on a pedal or by the owner via a smartphone app. In addition, next to the container there is a small camera. Whenever the animal or its owner triggers the opening of the container, a photo is taken and posted to the owner's Facebook.

The PetSafe automatic feeder is also a dog and cat feeder. The owner can schedule when feed should be made available and can also request feed dispatch remotely via a smartphone app. Smart Feed also monitors the feed level of the container. It can be set to notify owner when feed level is low or to order more feed automatically through Amazon Dash Replenishment (PETSAFE, 2019).

As noted in this section, there are works related to feeders, but most use cutting-edge technologies, focusing on computational resources, which adds a lot of value and make them inaccessible to small producers. Another feature is that remote access feeders are primarily focused on domestic animals. Among those destined for rural areas, few use the advantages provided by the Internet for remote control and monitoring, which motivated the development of the present work. The feeder developed aims to be a platform that allows inloco 
programming, without internet access, for the automatic treatment of animals, as well as allowing its customization so that it can integrate monitoring / remote activation resources using the Internet, and the main feature, from the use of low cost equipment / resources as well as scrap materials. 


\section{MATERIALS AND METHODS}

As the objective of this work is to propose a cheap solution for the automatic feeding of animals in rural areas, the feeder was built using a 50 liter plastic barrel, which is used as a storage container for the feed. At the base of the barrel, a Y PVC (Polyvinyl chloride) pipe was used as an outlet for the feed to be poured into the water. This pipe has a cover that can be opened or closed by a servo motor, the same used in satellite dishes. The whole mechanical part of the project was developed with scrap material. Figure 1 a) shows the side view of the physical structure of the feeder, while Figure $1 \mathrm{~b}$ ) shows the output of the feeder.

\section{Figure 1: a) Side view of the feeder. b) View of feeder output.}

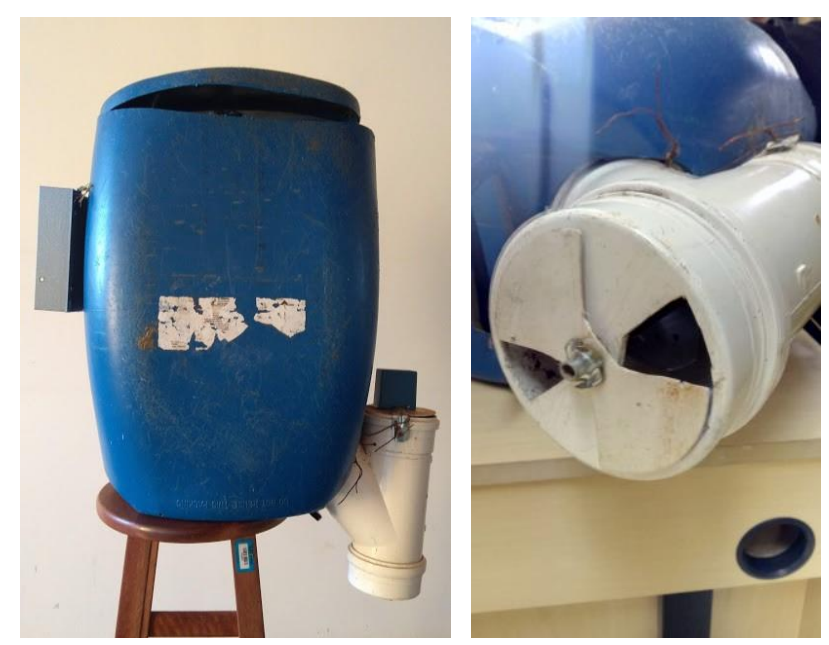

Source: Authored by the author.

Figure 2 shows a diagram with all feeder components.

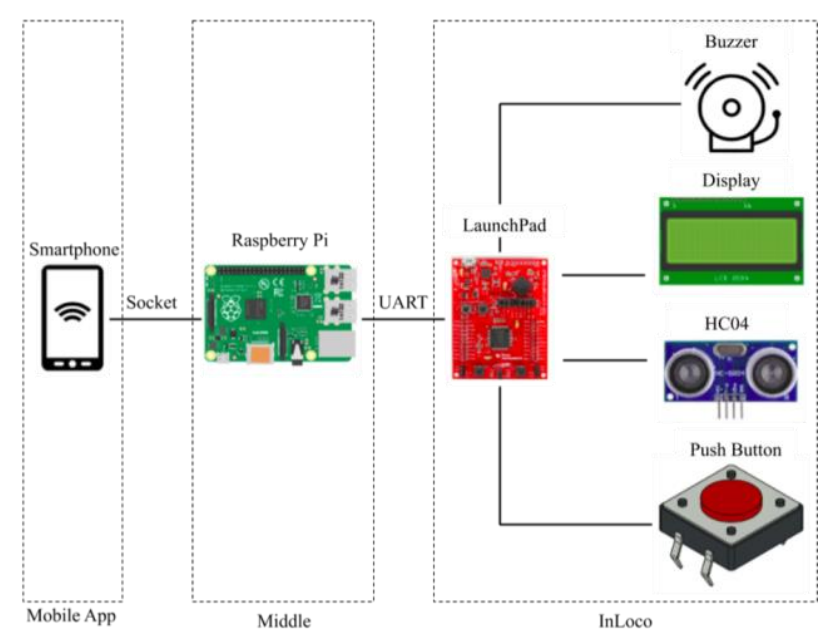

Source: Authored by the author. 
The feeder was automated using the Texas Instruments LaunchPad board. It is composed of the MSP430F5529, a 16-bit microcontroller with 128KB flash memory, 8KB RAM (Randomaccess memory) and a 25-MHz clock. It has 40 input / output pins, digital analog converter, 5 timers, among other features. The board is powered via USB (Universal Serial Bus) with a 5V operating voltage that can be reduced to $3.3 \mathrm{~V}$ using an integrated converter. LaunchPad has open source development tools such as Code Composer Studio and Energia (T. INSTRUMENTS, 2019).

The microcontroller drives the servo motor, which is responsible for opening and closing the storage container outlet lid, dumping the ration through gravity. Shortly after opening the lid, the microcontroller triggers a buzzer, emitting a sound wave that alerts animals near the feeder that is being fed to them. The opening of the lid happens at times set by the user, who can also configure how long he wants it to be open, allowing him to control the amount of feed provided. The feeder has an interface in which the user can configure when the drives will happen and how long they will last. This interface consists of an LCD (Liquid Crystal Display) display and buttons, as shown in Figure 3.

Figure 3: Feeder interface.

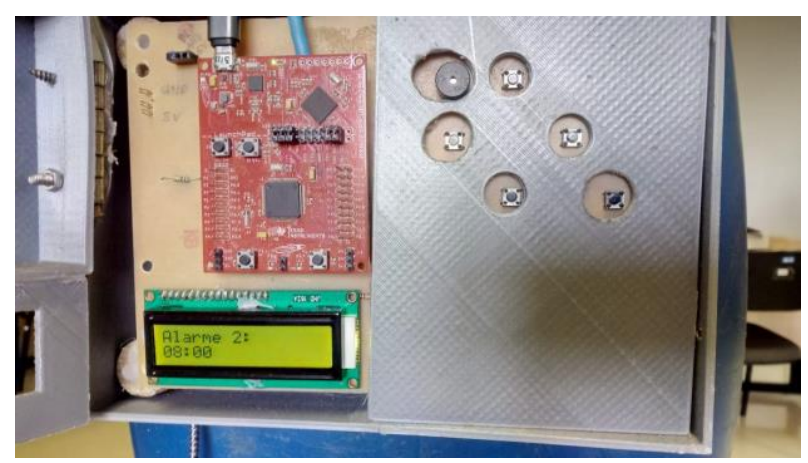

Source: Authored by the author.

The servo motor used was recycled from a satellite dish. Its operating voltage is $5 \mathrm{~V}$, with current between 180 and $200 \mathrm{~mA}$. The engine has a 180 degree rotation angle and maximum torque up to $2.8 \mathrm{~kg}$.

The microcontroller also reads a distance sensor that is inside the storage container. The HC04 sensor was used, an ultrasonic sensor that can provide distances from $2 \mathrm{~cm}$ to $400 \mathrm{~cm}$, with an accuracy of $3 \mathrm{~mm}$. This sensor serves to monitor the feed level. 5 values were set to define the level of feed in the container, 4 indicating that the container is full and 0 indicating that the container is emply. 
To power the system, a PowerBank $13000 \mathrm{~mA}$ with two 5V USB outputs up to $2.4^{\mathrm{a}}$ was used.

These are the componentes of the inloco part of the system that provide a simple and functional solution for automated feeding without using the Internet. Regarding the project costs, considering that the mechanical part was developed from scrap, it will not be considered in the total cost, only the costs with electronic components. The components used, as well as their costs, are listed in Table 1.

Table 1: Inloco hardware costs (in reais).

\begin{tabular}{c|c|c|c}
\hline Component & Amount & Unitary value & Total value \\
\hline \hline LaunchPad & 1 & 60.0 & 60.0 \\
\hline $\begin{array}{c}\text { Sensor } \\
\text { HC04 }\end{array}$ & 1 & 9.90 & 9.90 \\
\hline Buzzer & 1 & 4.90 & 4.90 \\
\hline $\begin{array}{c}\text { Push } \\
\text { button }\end{array}$ & 5 & 0.20 & 1.00 \\
\hline $\begin{array}{c}\text { Servo- } \\
\text { motor }\end{array}$ & 1 & - & - \\
\hline \multicolumn{2}{c}{ Total } & 75.80 \\
\hline
\end{tabular}

Source: Authored by the author.

Additionally, the feeder can be connected to the Internet via a Raspberry Pi board, which forms the middle of the feeder. The model used was Raspberry 3. It has Quad Core 1.2GHz 64bit processor, 1GB of RAM, 40 I / O pins, wireless connection, among other features (R.PI.RASPBERRY, 2019). Raspberry Pi acts as a server and exchanges information with a smartphone app. Through the app, the user can schedule lid opening times and also set how long it should be open remotely. It also has the option of starting the servo motor immediately if deemed necessary, allowing food to be dispensed ate any time. The app also enable feeder monitoring by providing information on battery level and feed level.

Smartphone application commands and requests are sent / received on Raspberry Pi via a socket interface, which is Always waiting for a request from the smartphone. When the application makes a request to Raspberry $\mathrm{Pi}$, that reques tis interpreted and made into na instruction for the microcontroller. These instructions are sent through a UART (Universal Asynchroinous Receiver / Transmiter) communication interface. For each request received, the microcontroller sends a message back to Raspberry $\mathrm{Pi}$, confirming that the requested action was performed successfully.

The smartphone app for remote feeder access was developed on Android as it is a free technology and free of charge for development. 


\section{RESULTS}

In order to make the present project adaptable, it was divided into three parts: inLoco, Middle and Mobile Application, for remote access, as shown in Figure 2.

\subsection{Inloco}

The inloco project consists of all the hardware required for the feeder to be able to operate automatically. It consists of the LaunchPad board with the MSP430F5529 microcontroller, which is responsile for driving the servo motor for opening the feeder output cover, buzzer triggering and monitoring the ultrasonic sensor. It can be configured by the user to provide food from time to time trough na interface with display and buttons.

If only the inloco part of the design is used on the feeder, it is fully functional, but does not allow access to information and the remote control, all operations must be done on the feeder through the buttons and the result of the operation is displayed.

\subsection{Middle}

The Middle consists only of a Raspberry Pi. Raspberry Pi serves as a medium between communicating with the Internet and the inloco part of the project. Raspberry Pi runs an application that receives commands from the smartphone application, and sends / requests data from the inloco part of the project. Data on Raspberry Pi is received through a socket. When the smartphone application makes a request to Raspberry $\mathrm{Pi}$, that reques tis interpreted and sent to te inloco via the UART communucation interface.

\subsection{App}

The app for remote communication has three screens. The main screen, described by Figure 4, has all data regarding the feeder, with feeding times, battery level and feed level. In the main screen there are still some buttons. The "configure"button gives access to the screen that allows schedule feeding times. The "manual"button allows opening the handler immediately. The "refresh"button allows manually update the information shown on the screen.

The second screen, descried by Figure 5, allows user to schedule feeding times. The user can register as many times as desired. For each scheduled time there is the option" change", allowing you to change the time, disableor delete the schedule.

In the third screen, described by Figure 6, the user can start the feeder immediately, also setting the opening time of the feeder output. 
Figure 4: Main screen.

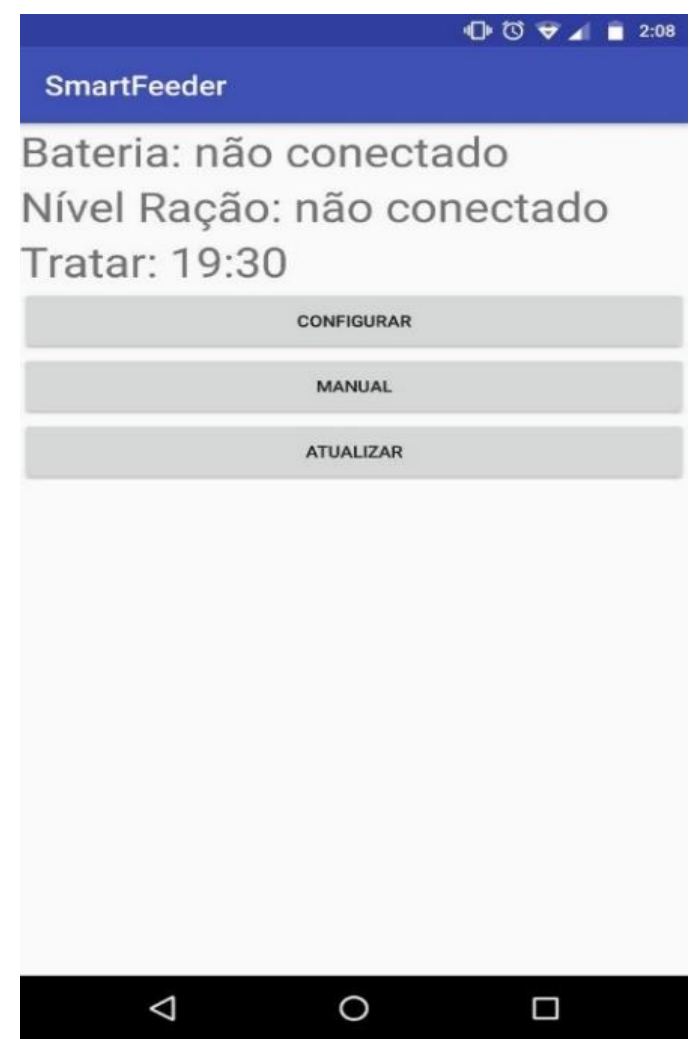

Source: Authored by the author.

\subsection{Hardware costs}

Table 1 shows the feeder hardware costs, in reais, for the inloco module. To add Middle, you should consider the cost of Raspberry $\mathrm{Pi}$, around 250 reais. As the smartphone app was developed using free tecnologies, it generated no costs. Thus, the feeder, already considering the Middle, can be implemented with a cost of about 325 reais. This figure is well below the values of remote access automatic feeders available in the Brazilian Market, since most of them are produced abroad and arrive heve with high costs. 
Figure 5: Screen for setting the feeding times.

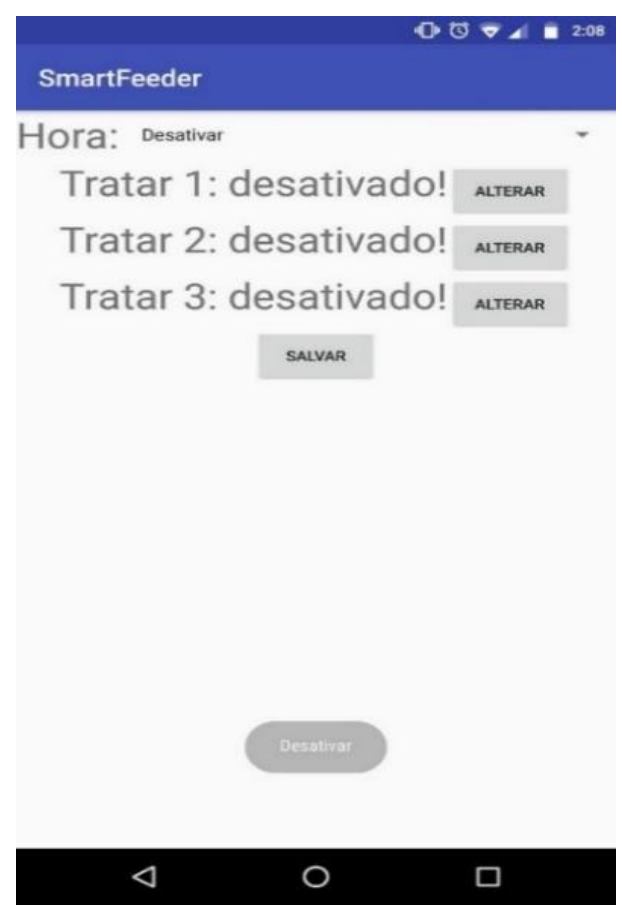

Source: Authored by the author.

Figure 6: Screen for manual feeding and buzzer activation

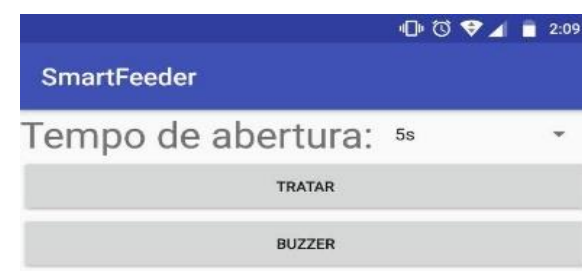

Tempo de Abertura: 5

$\triangleleft$

$\square$

Source: Authored by the author. 


\section{CONCLUSIONS}

The presente work presented the Project of a low cost automatic pet feeder, which makes use of scrap material and cheap eletronic componentes.

As a result, a feeder that can be used offline has been introduced, using only the inloco part of the Project, and can easily be adapted to become na online feeder, becoming na object of the Internet of Things scenario, with the use of a Middle, which will link the inloco Project with a smartphone application. For the Middle was used a Raspberry Pi.

The application that allows the remote control of the feeder was developed on the Android platform, since it is a free platform and its devices usually have a low cost.

Compared to comercial feeders that exist today, this Project has a much lower cost, costing on average 20 percent of the value of comercial projects with the same purpose.

Regarding the limitations of the system, the largest is in relation to the battery. Development was started using a popular 9V battery, the same ones sold in supermarkets, but inloco mode the battery lasted only a few days. So, to extend the battery usage time, it was decided to use a $13000 \mathrm{mAh}$ PowerBank, wich significantly increased project uptime without recharging. 


\section{REFERENCES}

A. SUDOESTE. Alimentador tratador automático 181 cães, gatos, aves, peixes, 2019

HWANG. NURIPET: A smart pet feeding machine for sns. In IEEE International Conference on Consumer Electronics (ICCE), 2016, pages 117-118, Las Vegas, 2016.

J.-Y. JUNG, C.-M. Ji, J.-R. Sohn, H.-J. Meng, and B.-S.

K. K. KISHORE, P. V. Krishna, and D. Srikanth.

Automatic feeding system for aquaculture. In Third International Conference on Sensing, Signal Processing and Security (ICSSS), 2017, pages 426-429, Chennai, 2017.

PETNET. Petnet smart feeder, 2019.

PETSAFE. Smart feed automatic dog and cat feeder, 2 nd generation, 2019.

R. PI. RASPBERRY pi 3 model b, 2019.

S. DAVIDSON. Open-source hardware. IEEE design \& test of uters, 21(5):456-456, 2004.

T. INSTRUMENTS. Msp430f5529 usb launchpad evaluation kit, 2019.

Z. H. C. SOH, M. H. Ismail, F. H. Otthaman, M. K. Safie, and M. A. A. Zukri. Development of automatic chicken feeder using arduino uno. In International Conference on Electrical, Electronics and System Engineering (ICEESE), 2017, pages 120-124 , Kanazawa, 2017. 